\title{
ANALYSIS OF PERFORMANCE
}

OF A ROCKET-BORNE

RETARDING POTENTIAL ANALYZER

\author{
Oscar P. Manley \\ American Sclence and Engineering, Inc. \\ 11 Carleton Street \\ Cambridge 42, Massachusetts
}

Contract AF $19(604)-8849$

Project No. 8653

Task No. 865302

This research is sponsored by the Washington, D. C. Defense Atomic Support Agency under Deb. No. 07.007.

\author{
FINAL REPORT
}

May 1964

Prepared

for

AIR FORCE CAMBRIDGE RESEARCH LABORATORIES

OFFICE OF AEROSPACE RESEARCH

UNITED STATES AIR FORCE

BEDFORD, MASSACHUSETTS 


\section{DISCLAIMER}

This report was prepared as an account of work sponsored by an agency of the United States Government. Neither the United States Government nor any agency Thereof, nor any of their employees, makes any warranty, express or implied, or assumes any legal liability or responsibility for the accuracy, completeness, or usefulness of any information, apparatus, product, or process disclosed, or represents that its use would not infringe privately owned rights. Reference herein to any specific commercial product, process, or service by trade name, trademark, manufacturer, or otherwise does not necessarily constitute or imply its endorsement, recommendation, or favoring by the United States Government or any agency thereof. The views and opinions of authors expressed herein do not necessarily state or reflect those of the United States Government or any agency thereof. 


\section{DISCLAIMER}

Portions of this document may be illegible in electronic image products. Images are produced from the best available original document. 


\section{FOREWORD}

This document is the Final Report on Contract AF 19 (604)-8849. The successful completion of the work on this contract was due in large measure to the help and guldance of Drs. W. Pfister and R. Vancour, Messrs. J. Ulwick and J. Sandock, all of Alr Force Cambrldge Research Laboratories. The author wishes to acknowledge further the patience and understanding of Drs. I. Carpenter and S. Frankenthal, as well as the useful discusstons with Messrs. O. Anderson and Y. Treve, all of American Sclence and Englnearing, Inc. Others who gave willingly of their time and knowledge were Professors S. Olbert and J. Baron, as well as Dr. H. Bridge, of MIT. 


\section{ABSTRACT}

The use of a rocket-bome retarding potentlal analyzer (RPA) for determining positive lon densitles in the lonosphere is studied. It Is shown that at the altitudes of interest $(40$ to $90 \mathrm{~km})$ shock ionization Induced by the nose-cone may exceed amblent Iontzation. Moreover, the positive Ion current measured by means of the RPA is not linearly dependent on the lon density; at present, the precise functlonal dependence between the two quantitles cannot be established analytlcally. 
INTRODUCTION .................... I

II

AERODYNAMIC PERTURBATIONS . . . . . . . . . 


\section{LIST OF ILLUSTRATIONS}

Flgure

Page

1

Sketch of the Retarding Potentlal Analyzer ........ 2

2 Velocity Proflle (N1ke-Cajun) ............. 5

3 Velocity Proflle (Black Brant IIa) ........... 6

4 Ionization of Air Versus Temperature and Denstty.... 7

5 Density Dependence of Coefficlents $A$ and $B$ in

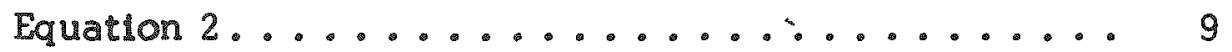

6 Estimated Ionos pherlc Charge Densittes and

Nose Cone Shock Iondzation .............. 10

7 Comparison of Characteristic Lengths ......... 13

8 Potentlal Dlstribution ................. 15

9 Generation of a Double Probe Characteristlc...... 18

10 Generation of a Double Probe Characteristic....... 19

11 Princlpal Dimensions of N1ke-Cajun Nose Cone .... 21

12 Effect of Serles Resistance on Probe Characteristic . . 23

13 Superposed Probe and Sheath Flelds ......... 26

14 Photoelectric Effect on an Insulated Plate ...... 30 
CHAPTER I

\section{INTRODUCTION}

The principal objective of this research program was to establish the extent to which a rocket-borne retarding-potential analyzer (RPA), Figure 1, can be used to measure ambient positive lon densities in the lower ionos phere. At one time it was thought that such an instrument could be used to determine the positive lon densitles to within better than $10 \%$. Since ambient electron densitles can be determined very accurately by a varlety of Independent methods, it appeared that one could thus determine the altitude dependence of negative Ion concentration by simply taking the difference of the measured positive lon and electron densitles on the assumption of charge neutrallty in the lonosphere. Unfortunately, a careful review of some of the relevant factors reveals that without the prior understanding of some important entities it is not posstble to interpret uniquely and accurately the data obtained with the RPA. For order of magnitude estimates of positive ion densities the RPA is of unsurpassed value being a very simple and foolproof device. However, as indicated in this report, it is of questionable value as a precise quantitative measuring tool. The principal reason for this rests with the Inherent perturbing action of the probe with respect to its environment. The two types of perturbations dealt with in the present work are:
a) aerodynamic, and
b) electrostatic. 


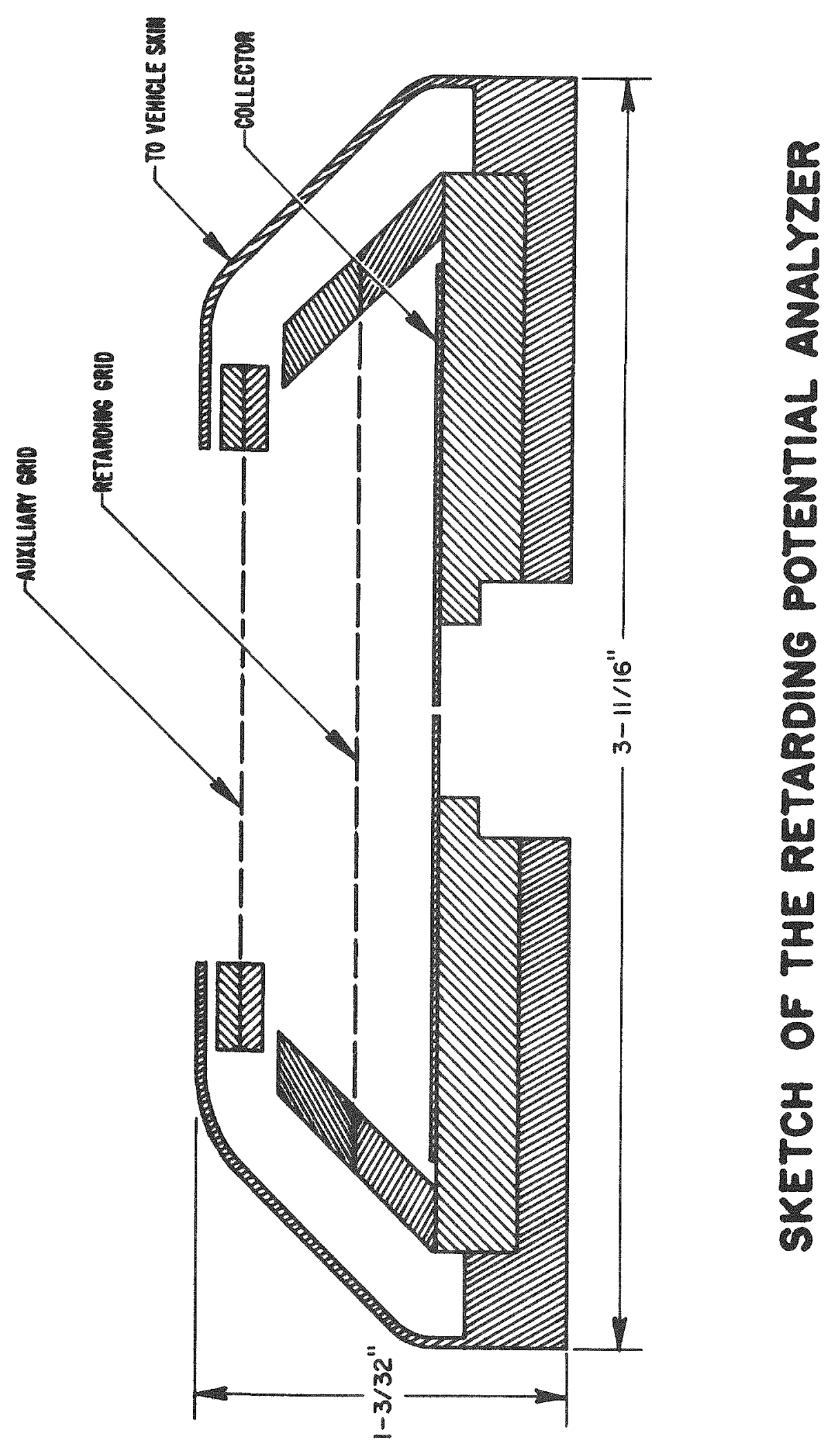


As will be seen presently, while some measure of control can be oxerclsed over the first type of perturbation, little, If anything, can be done about the second. 


\section{CHAPTER II}

\section{AERODYNAMIC PERTURBATIONS}

In this section, it will be shown that the amblent lon density In the Lonosphere may be affected by the passage of a suffictently fast rocket. Spectfically, It will be shown that a nominal change in the local Mach number may have a large effect on the amblent lon density.

When a body such as a rocket nose cone moves through alr at a speed greater than that of sound, a shock wave forms. The maximum temperature, $T_{m}$. In the shock occurs at the stagnation point and is given by (Reference SI)

$$
\frac{T_{m}}{T}=\left(1+\frac{M^{2}}{5}\right)
$$

where $\quad T_{\text {is the ambient temperature, and }}$

$$
\mathrm{M} \text { is the Mach number. }
$$

Figures 2 and 3 show the Mach number versus altitude for two flight plans typical of, say, Nike-Cajun and Black Brant nose cones, respectively.

From the asymptotlc behavior of published computations of lonized components of heated air, Flgure 4, (Reference GI), it is found that for $\mathrm{T}<3000^{\circ} \mathrm{K}$ the electron denslty, $\mathrm{n}_{\mathrm{e}}$, as a function of temperature is given by 


\section{VELOCITY PROFILE \\ NIKE-CAJUN}

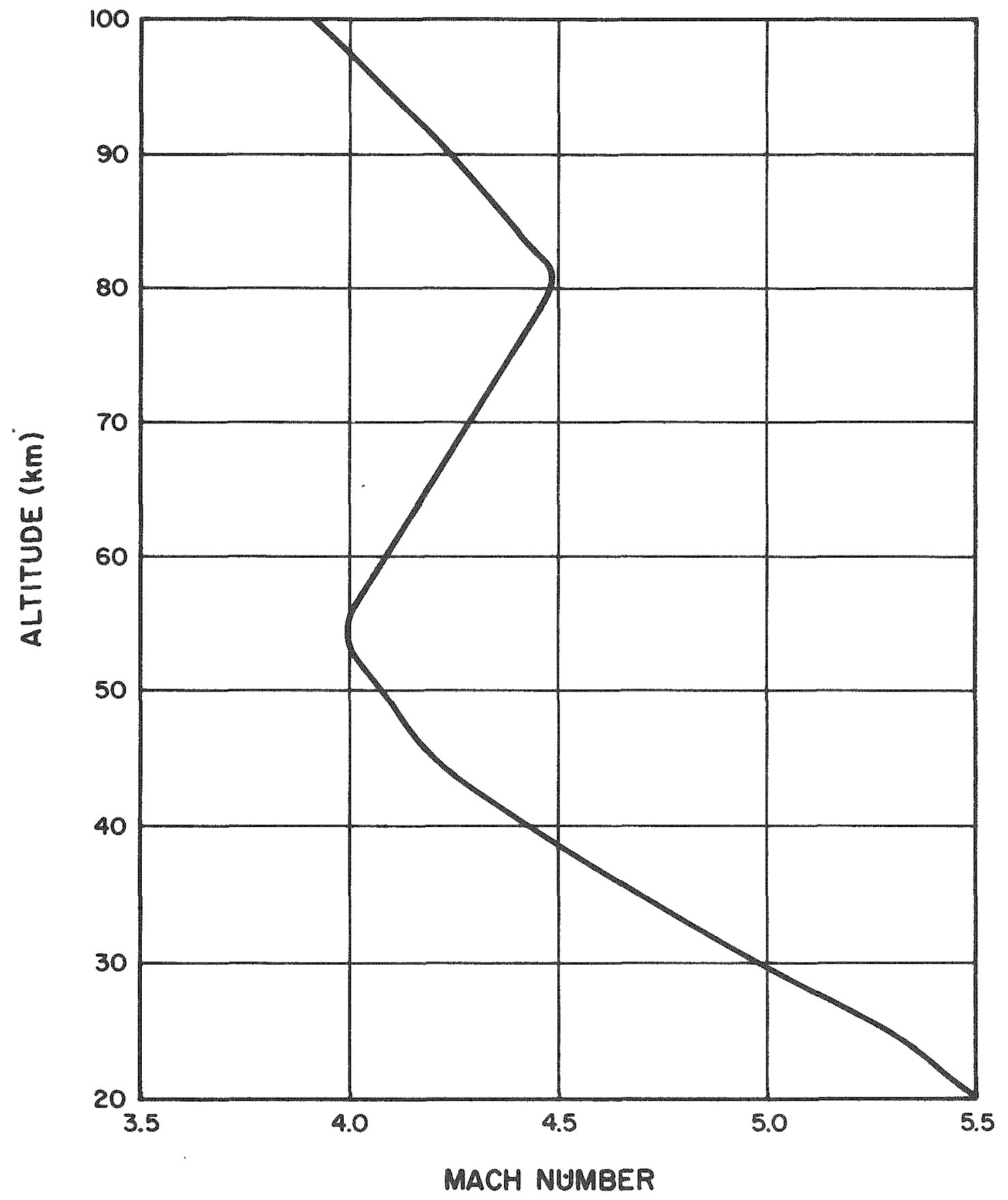

Fig. 2 


$$
Y=
$$




\section{IONIZATION OF AIR VS. TEMPERATURE AND DENSITY}

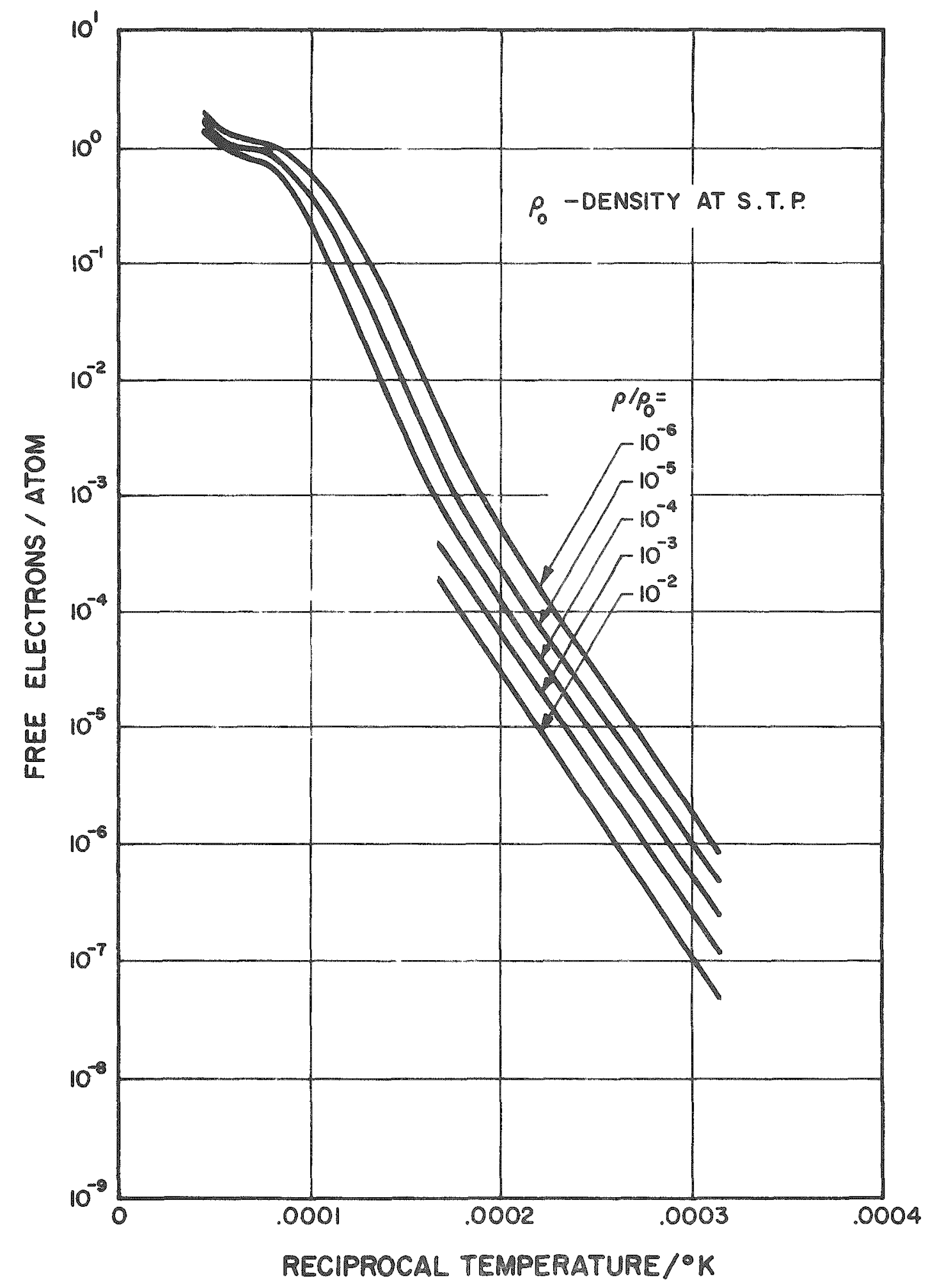




$$
n_{e}=\rho A e^{/ \tau}
$$

where $\rho$ is the amblent number density at the altitude of interest, and $A$ and $B$ are functions of density, Flgure 5. According to Reference GI. In this temperature range there are no signiflcant negative lons and the most Important positive Ion species is $\mathrm{NO}^{+}$. Upon using in Equation (2) the stagnation point temperature, $T_{m}$, as determined from Equation (1) and combining with the required densities and ambient temperatures as given by the Model Atmosphere (M1), it is possible to determine the maximum ionization due to aerodynamic heating. This has been done for the flight plans illustrated in Figures 2 and 3 and the results plotted in Figure 6. This figure shows for comparison the estimated ambient day and night lonization (C1). It is seen that a slowly moving vehicle such as Nike-Cajun does not add significantly to the amblent Ion density above, say, $40 \mathrm{~km}$. On the other hand, a little more rapldy moving nose cone may contribute signiflcantly to the ambient ion density up to $90 \mathrm{~km}$.

Therefore, it seems that it is possible to avold aerodynamic perturbations of ambient ionization by carefully scheduling flight plans such that the nose cone moves relatively slowly through the region in which measurements are made. 


\section{DENSITY DEPENDENCE OF COEFFICIENTS A AND B IN EQUATION 2}

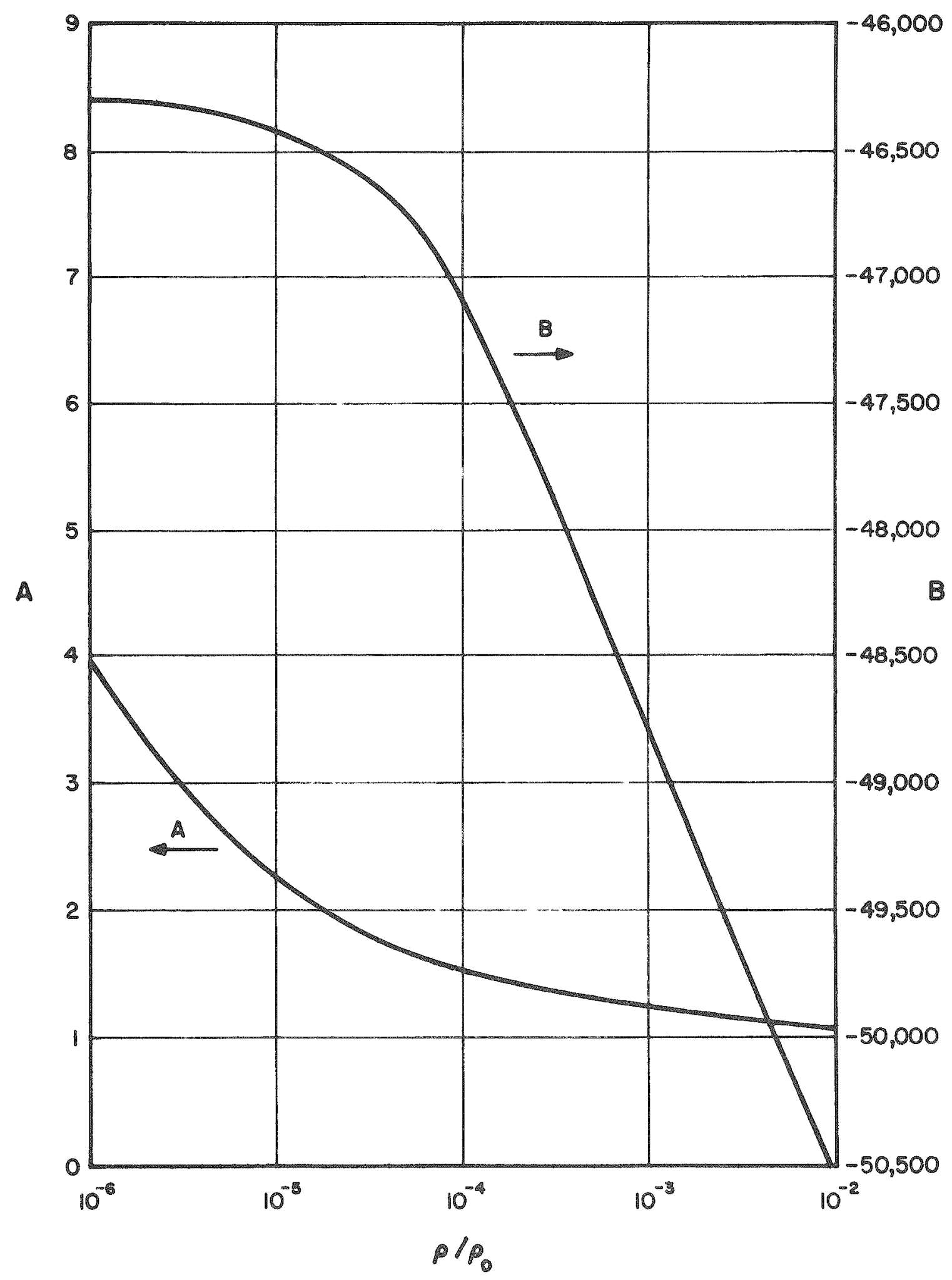

FIg. 5 


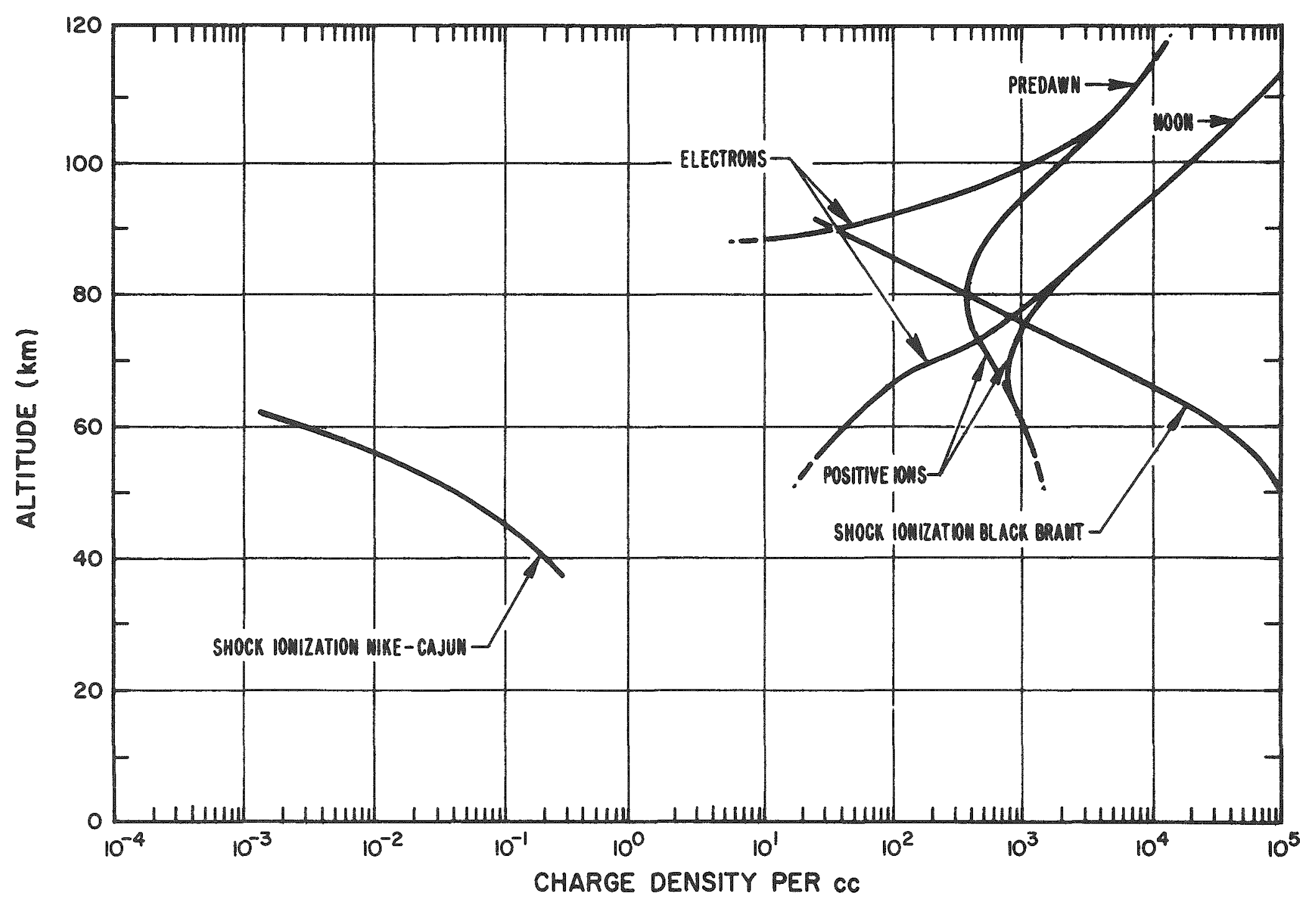

$\frac{7}{6}$ 
CHAPTER III

\section{ELECTROSTATIC PERTURBATIONS}

The use of an RPA for measurement of positive lon density stems from the assumption that under saturation conditions - the motion relative to the medium belng negligible, e.g., at apogee or in the case of side detectors the positive lon current to the probe, $I_{+}$, is given by (HI)

$$
I_{+}=\mathrm{Cn}_{+} \sqrt{\mathrm{T}_{+}} \mathrm{A}
$$

where

$$
\begin{aligned}
& \text { C is a constant, } \\
& n_{+} \text {is the amblent postive lon density, } \\
& \text { A is the geometrical area of the collecting electrode, and } \\
& \mathrm{T}_{+} \text {is the positive ion temperature. }
\end{aligned}
$$

As will be shown, every assumption behind Equation (3) is questionable, and therefore Equation (3) is never strictly valld.

To begin wlth, the dependence of $\mathrm{I}_{+}$on $\mathrm{T}_{+}$derives from two assumptions: first, that ions which arrive and are absorbed at the probe have a Maxwellian distribution; and second, that this distribution is characterized by the ambient Ion temperature, $T_{+}$. It is now well known that neither of these assumptions is true (B1, B2, L1). It turns out that the assumption of Maxwellian distribution for the lons in the vicinity of the probe leads to a violation of charge neutrallty at a large distance from the probe. With respect to the second assumption, in the absence of collistons, the motion of the positive lons in the vicinity of the probe Is governed by the existence of a sheath. But the electrostatic potential assoclated with this sheath 15 governed by the most moblle charged species present, 1.e., by electrons; hence, the motion of the positive Ions is a function of the electron temperature, $T_{e}$, rather than the ambient postlve lon temperature $T_{+}$. 
Further studies ( $\mathrm{Al}$ and $\mathrm{B} 3$ ) show that the effective collecting area of the probe is determined principally by the slze of the sheath rather than by the geometric area, A. Since the size of the sheath depends on the electrostatic field distribution, including externally imposed accelerating or decelerating fields, saturation never really occurs and, hence, the region of validity of Equation (3) is extremely 1ll-defined.

In order for the analysis of the RPA data to be independent of the composition of the lonized gas, it is necessary that

$$
\lambda_{D}<\ell
$$

where $\quad \lambda_{D} \simeq \sqrt{\frac{T}{n_{e}}}$ is the Debye length in $\mathrm{cm}$,

$\ell$ is the collision mean free path in $\mathrm{cm}$, and

$\mathrm{n}_{e}$ is the electron density in number $/ \mathrm{cm}^{3}$.

This condition insures that the motion of both ions and electrons is governed by the electric potential in the vicinity of the probe in the absence of collisions; thus, the relevant collision cross-sections need not be known. For the same reason, it is required that

$$
\mathrm{L}<<
$$

where $\mathrm{L}$ is a characteristic Innear dimension of the probe. Moreoever, in order for the geometry of the probe to determine the effective current collection area, it is necessary that

$$
\lambda_{D}<L<<l .
$$

If this condition is not satisfled, as stated above, the effective collection area is governed by the thickness of the sheath which in turn varies with the potential of the probe referred to the unperturbed lonized gas. Figure 7 shows that condition (4) is not satisfied below about $95 \mathrm{~km}$.

We shall discuss presently some of the problems encountered in using this device below $95 \mathrm{~km}, 1$. e. , when collisions must be accounted for. But first, let us briefly indicate some of the difficulties encountered in interpreting 


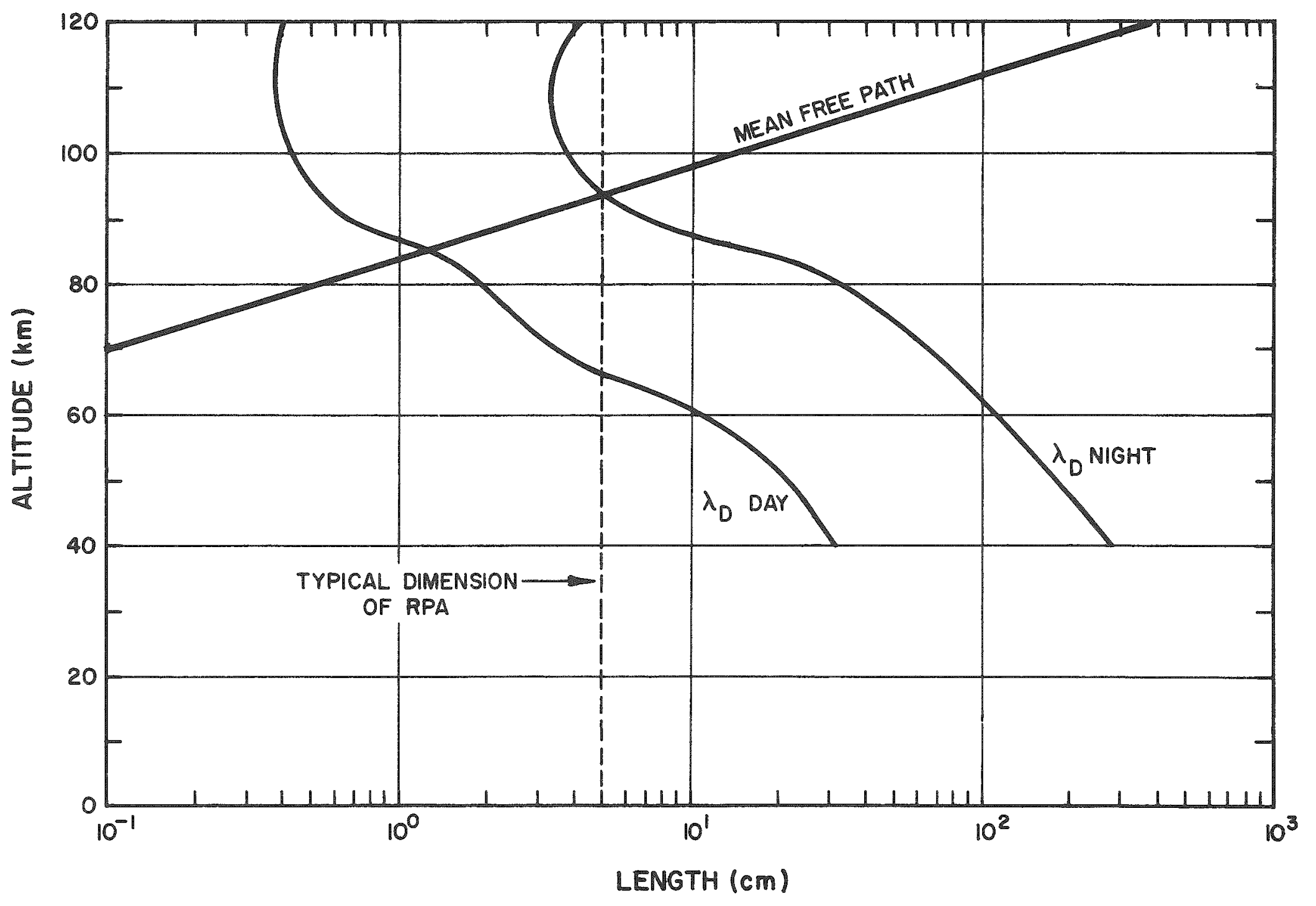

COMPARISON OF CHARACTERISTIC LENGTHS 
the data obtained above $90 \mathrm{~km}$. For the sake of simplicity, the motion of the rocket relative to the lonosphere will be neglected. As indicated by Boyd (B4), the rocket and the analyzer constitute an asymmetric double probe. This is obvious when one exhlblts the electric equivalent circuits as in Figure 8 and regards the skin of the vehicle and the auxiltary grid as the two elements of the double probe. The potential distribution inside the analyzer is drawn on the assumption that the exterlor plasma does not penetrate into the analyzer. The potential of the retarding grid varies between $V_{\mathrm{rmin}}$ and $\mathrm{V}_{\mathrm{rmax}}$ as required. The skin of the vehicle is at a potential $\mathrm{V}_{\mathrm{S}}$ with respect to the plasma. $V_{s}$ is an implicit function of $V_{a}$ and $V_{p}$ where $V_{p}$ is the plasma potential (LI). The reason for the existence of $V_{p}$ is that an uncharged surface Immersed in an lonized gas in thermal equilibrium will acquire a net steady state charge of the sign corresponding to the most mobile charge component. As a result of this charge, the surface acquires a potential, $V_{p}$, with respect to the unperturbed lonized gas given by (Reference L2)

$$
V_{p}=-\frac{k T}{e} \ln \frac{M_{t}}{M_{-}}
$$

where

$$
\begin{array}{ll}
\text { k } & \text { Is Boltzman constant, } \\
\text { T } & \text { Is the thermal equilibrium temperature, } \\
\text { e } & \text { Is the electron charge, and } \\
M_{+} \text {and } M_{-} \text {are the masses of the positive and negative } \\
\text { charge carriers, respectively. }
\end{array}
$$

It must be stressed that Equation (5) is valid only if the positive and negative charge carriers have Identical temperatures, T . If they do not, and the negative charges are predominantly electrons, the approprlate temperature turns out to be the electron temperature, say $T_{e}$. The spatial extent over which the potential $V_{p}$ perturbs the lonlzed gas is estimated at several Debye-lengths (Reference B3). 


\section{POTENTIAL DISTRIBUTION}

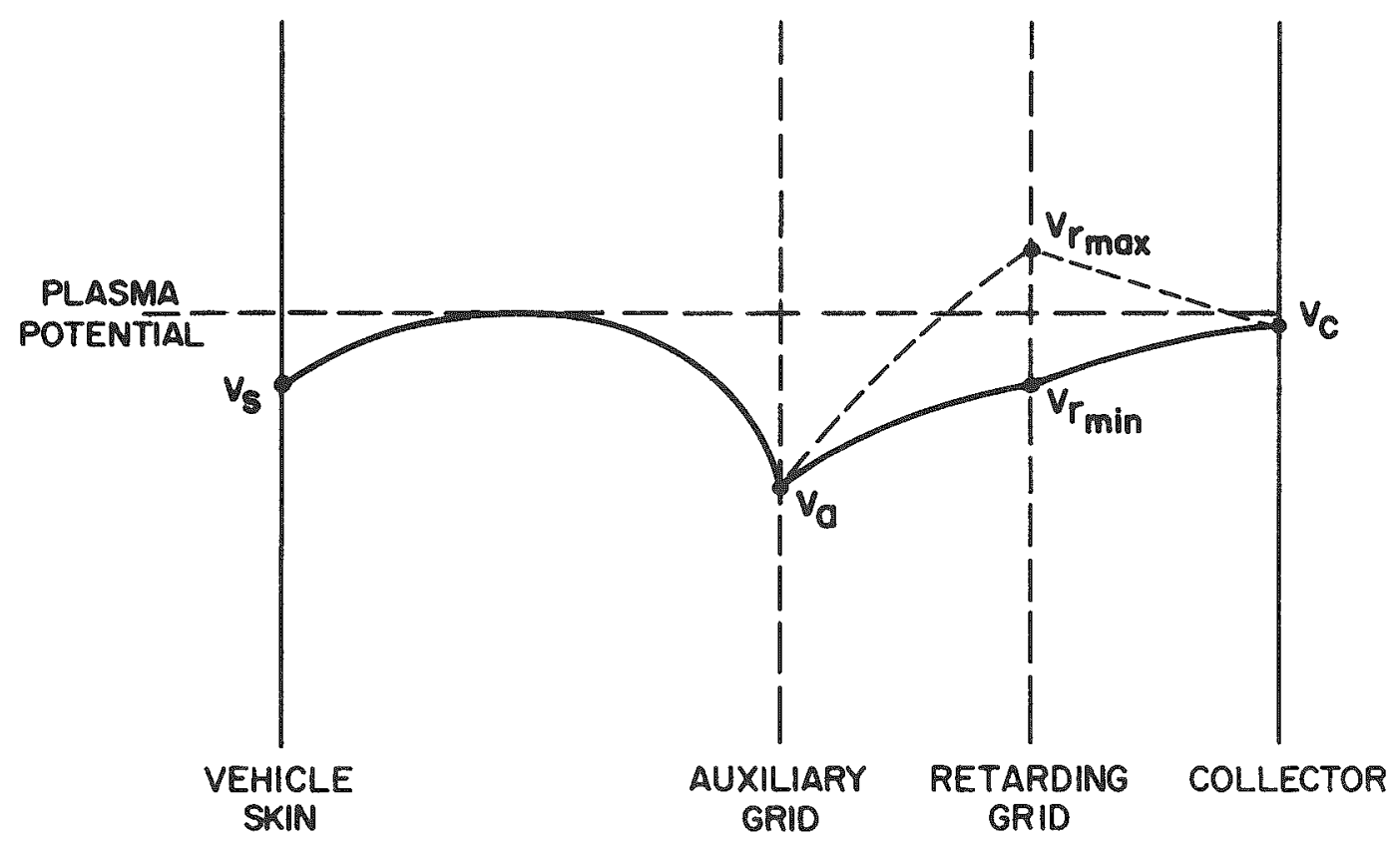


For the case of a significant fraction of negative ions, see Reference B5. Suffice it to say here that the theory is very comlicated and some ambiguitles remain in interpreting experimental data. The reason why that theory is not of immediate concern in the present context is that it is valid when collisions are not important, while in the lonosphere negative lons outwelgh electrons only where collisions must be taken into account.

Johnson and Malter (Reference JI) as well as L. G. Smith (Reference S2) have discussed the $1-v$ curve of an Idealized double probe in purely analytic terms. Here, we shall indicate how to analyze graphically the behavior of a double probe - this is especially useful when the $1-v$ curves are not representable in analytic terms (References H2 and F1). Apart from that, the approach presented here Illuminates some key features of an asymmetric double probe which are almost independent of the analytic expression for the $1-v$ curves. Let $A_{I}$ be the area of the probe element corresponding to the lateral surface of the rocket and let $A_{\text {II }}$ be the area of the element corres ponding to the RPA. Assume that the operating conditions are such that the sheaths of the two elements do not overlap and that the single probe characteristics of each element exhibit near-saturation currents for both large negative and positive voltages $-I_{e}$ and $I_{p}$, respectively. Consider first the case where

$$
I_{e I I}>I_{p I}
$$

Hereafter, subscript I Is assoclated with $A_{I}$ and subscript II is associated with $A_{\text {II }}$. This implles that 


$$
1<\frac{A_{I}}{A_{I I}}<\sqrt{\frac{M_{t}}{M_{-}}} .
$$

The double probe characteristic is obtained by considering one of the probe elements, say $A_{\text {II }}$, as a load curve Imposed on the $v-1$ curve for the other probe, $A_{I}$ in this case. By sliding one curve past the other, as indicated in Figure 9a, the double probe $d_{b}-v_{b}$ curve is generated - see Figure 9b. It is obvious that as long as condition (6) holds, the current $i_{b}$ through the plasma to the probes is made up principally of positive charges and, hence, neither element of the probe can be driven positive with respect to the plasma potential (Figure 9c) (cf, B4). Consider now the situation illustrated in Figure 10a where

$$
I_{e I I}<I_{p I}
$$

1. e. , roughly

$$
\frac{A_{I}}{A_{I I}}>\sqrt{\frac{M_{t}}{M_{-}}} .
$$

As curve II slides past curve $I$, the resulting double-probe $i_{b}-v_{b}$ curve thus generated is approximately a replica of the single probe characteristic II except for shifted axes of reference. Of course, this implies that when condition (8) holds, the smaller element can be driven positive with respect 


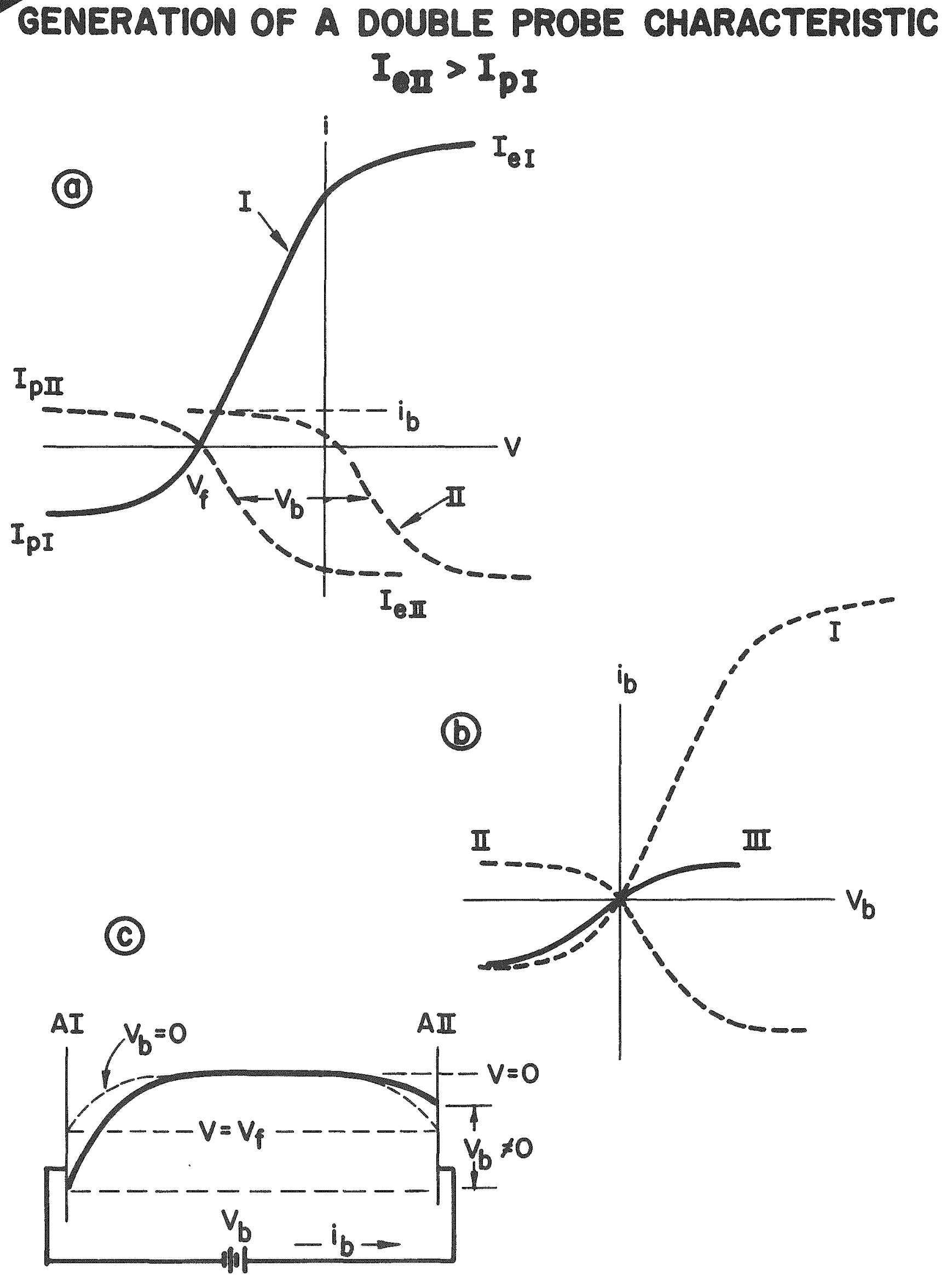

Fig. 9 
GENERATION OF A DOUBLE PROBE CHARACTERISTIC $I_{\text {II }}<I_{\text {PI }}$

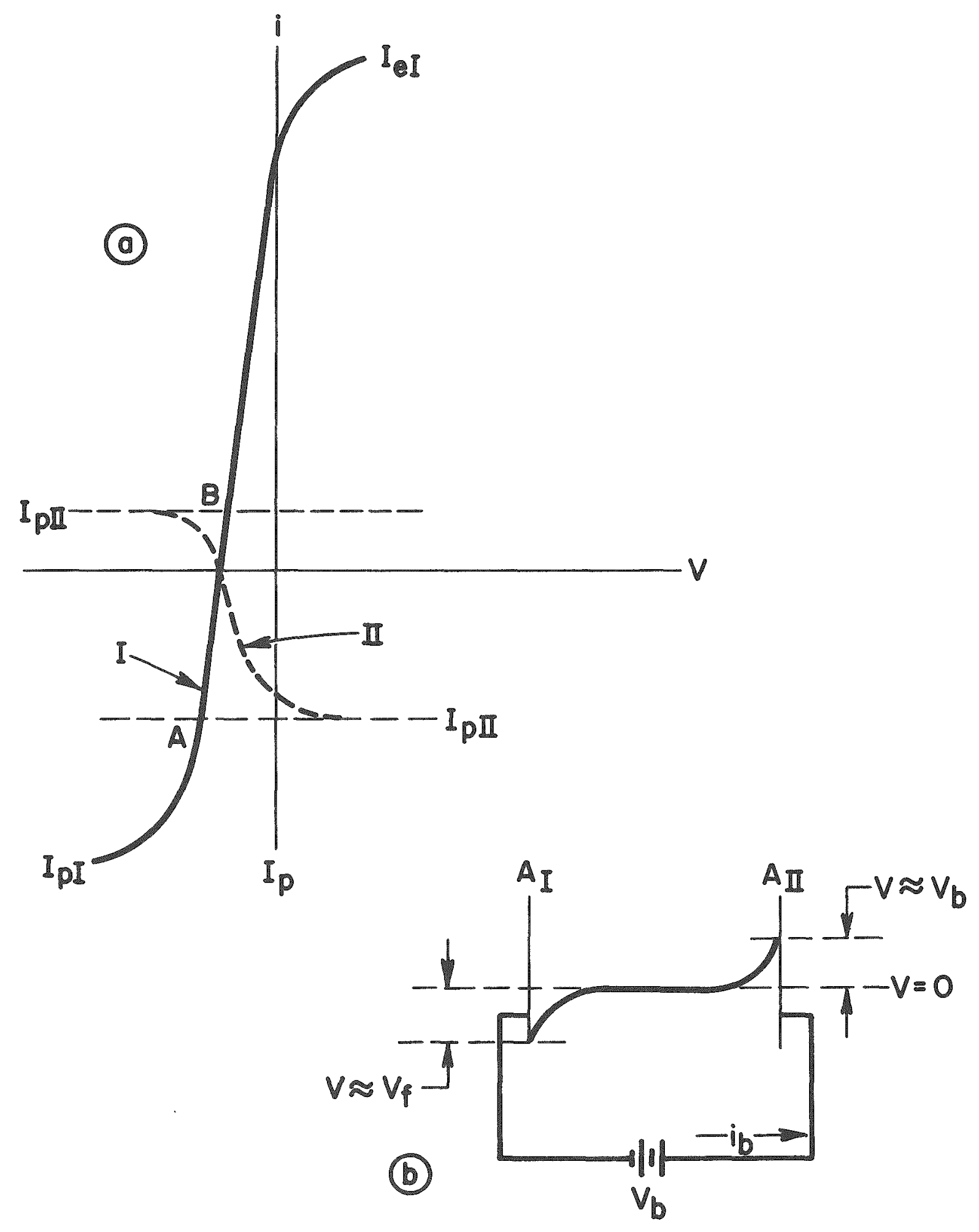

Fig. 10 
to the plasma potential and hence for large $v_{b}$, the near saturation current can be regarded as made up largely of electrons. Note that if the segment of curve I between A and B were vertical, an exact replica of II would result. This can be achleved to an arbitrary extent by making condition (9), and hence (8), more stringent:

$$
\frac{A_{I}}{A_{I I}} \gg \sqrt{\frac{M_{t}}{M_{-}}} .
$$

For the case of the ionos phere, this implies

$$
\frac{A_{I}}{A_{I I}}>250
$$

For the potential analyzer discussed here mounted on, say, a Nike-Cajun (Figure 11)

$$
\frac{A_{I}}{A_{\text {II }}} \approx 250
$$

Thus, the probe parameters are in a region which makes it extremely difficult to interpret the data. From the preceding discussion it is self evident that it is practically impossible to obtain a situation where the potential of $A_{I}$ is positive with respect to the plasma and hence no significant electron current can be drawn by $A_{I}$ from the plasma. 


\section{PRINCIPAL DIMENSIONS OF NIKE-CAJUN NOSE-CONE}

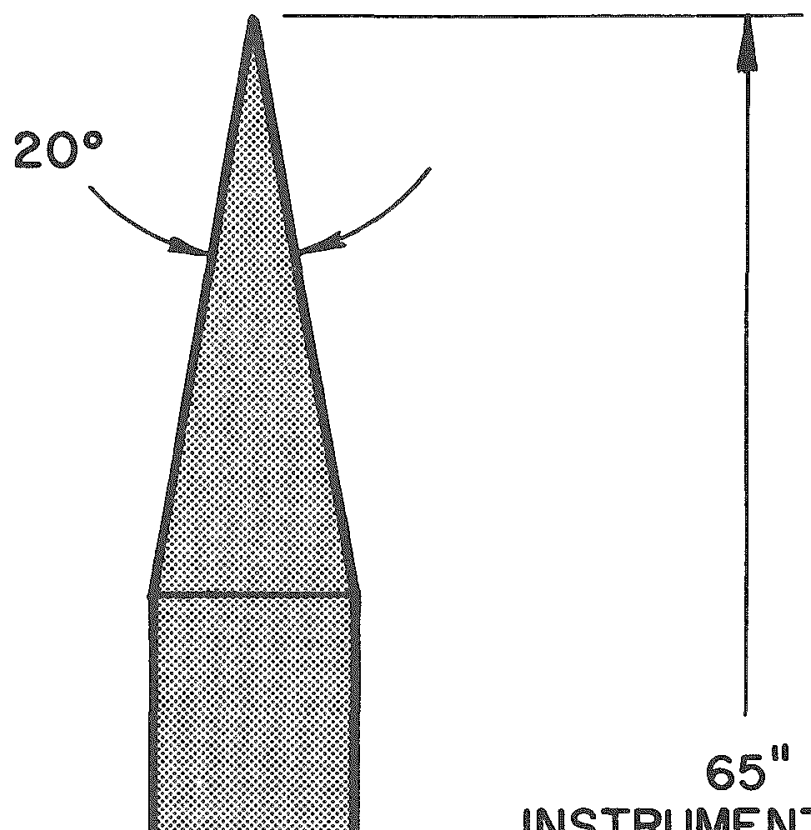

INSTRUMENTATION

$6.75^{11}$

DIA.
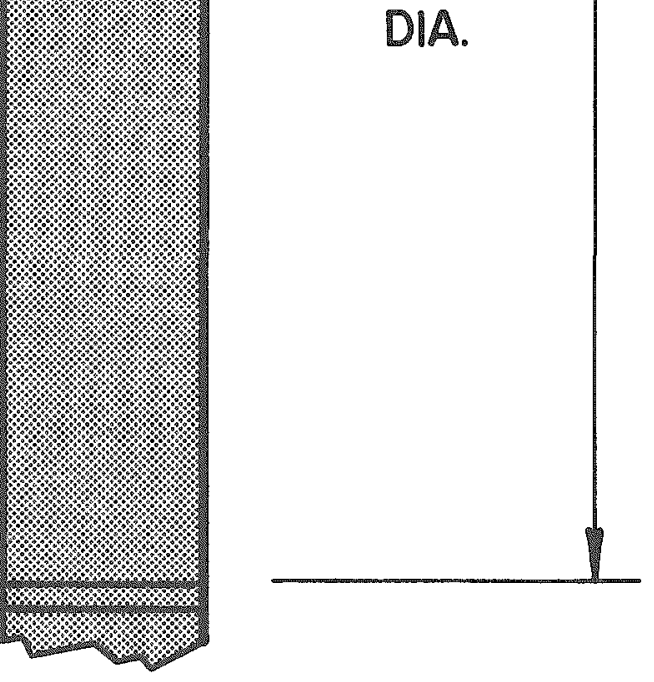

FIg. 11 
As Indlcated by Boyd (B4), for a successful operation of the rocketborne probe, the current flow must not be limited by the rate with which positive ions recombine at the surface of the rocket. In order to gain an insight Into the problems which arise when such a limitation does exist, assume that the effect of impeded recombination can be represented by a Iinear resistance $R$ - a gross oversimplification! - and further assume for the sake of argument that the double probe $1-v$ curve can be approximated by a plecewise linear curve (curve I in Figure 12). The effect of resistance $R$ is shown in curve II . Note that the break points have been shifted and, hence, considerable error may be introduced Into the determination of the floating potential, $V_{f}$, and as well as the electron temperature, $T_{e}$ (cf. L1). Attention is drawn to the fact that if the surface of the rocket is painted $(R \rightarrow \infty)$, the effective area $A_{I}$ may be smaller than $A_{I I}$.

It should be noted that where the Debye length is not very much smaller than the dimenstons of the probe, the sheaths of the two probe elements rocket surface and the analyzer - overlap and, hence, the system must not be treated as a double probe. To see what occurs under these conditions, consider a small conducting disc of radius a mounted in a hole cut out a a large plane conducting surface. Let this arrangement be exposed to a weakly Ionized gas such that the sheath that forms at floating potential is about equal to the radius of the small disc, $1 . e$. ,

$$
\lambda_{\mathrm{D}} \approx \mathrm{a}
$$

Further, let the disc be placed at a voltage, $V_{0}$, negative with respect to the plane.

Such an arrangement is admittedly not a very good approximation to the analyzer imbedded in a cylinder of nearly equal radius. However, it can be treated analytically and it offers an insight into the behavior of an asymmetric 


\section{EFFECT OF SERIES RESISTANCE ON PROBE CHARACTERISTIC}

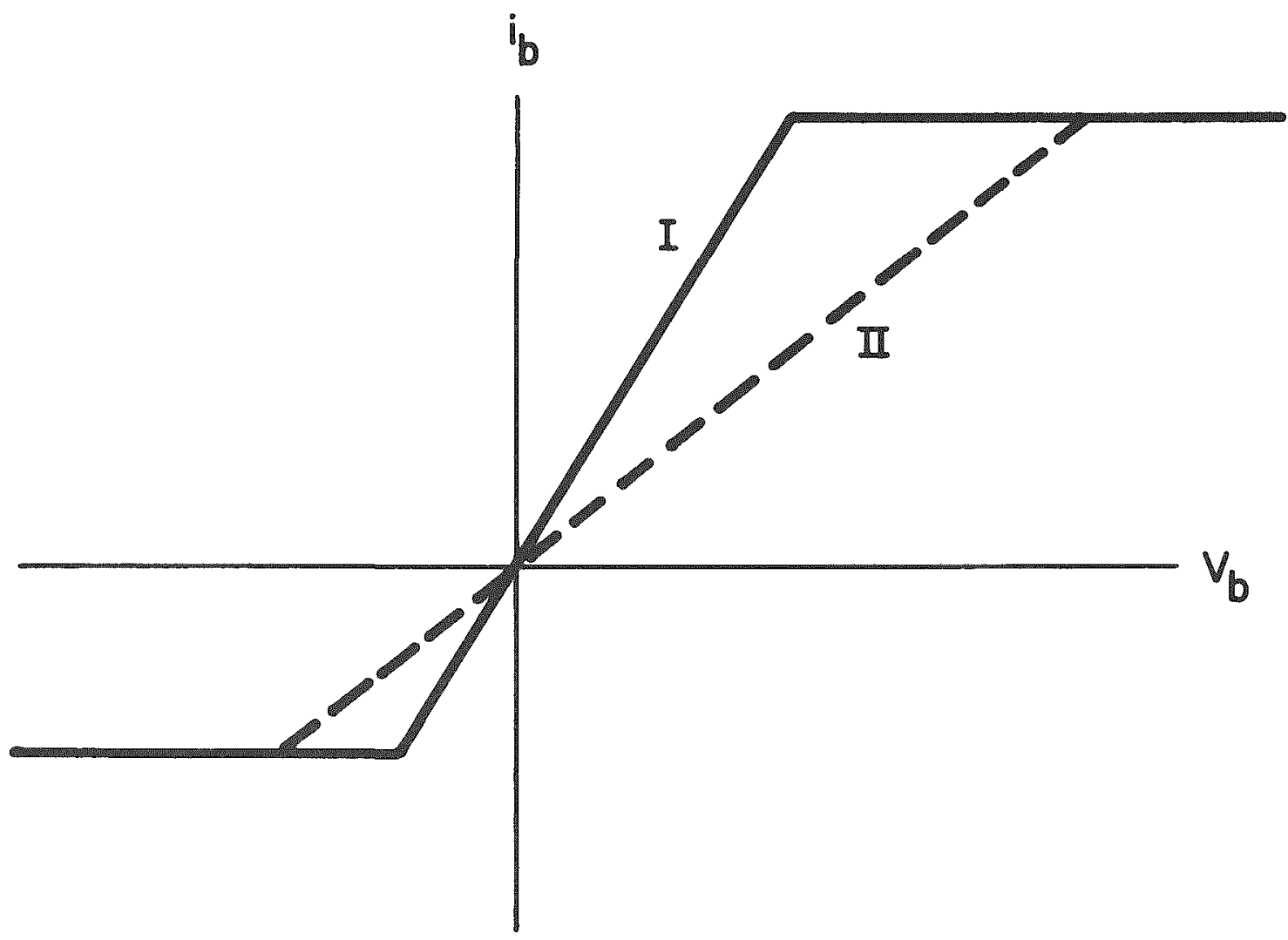

I

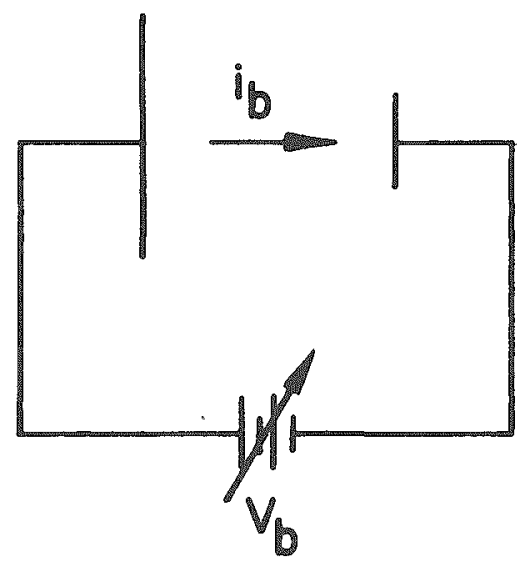

III

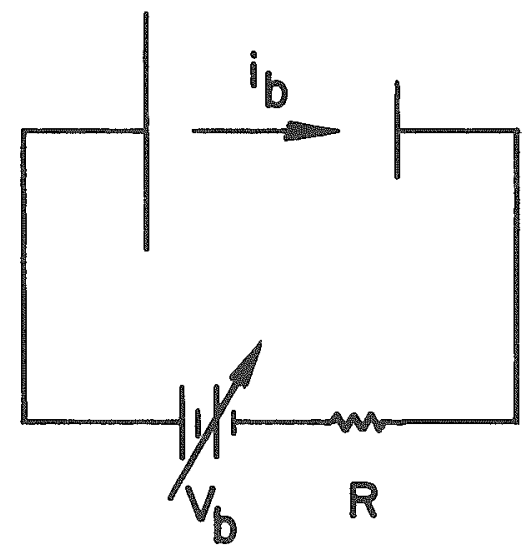

Fig. 12 
double probe whose sheaths have merged.

To the first approximation, it will be assumed that the potential distribution in front of the plane is given by superposing the potential associated with the sheath onto the potential of the plane and the disc in the absence of the plasma. Obviously, this cannot be universally true because the sheath potential distribution is arrived at by assuming a field tree region in the absence of the plasma and vice versa. However, it is felt that the significant features may be elucidated by this simple approximation. Under these assumptions, the potentlal distribution $\psi(r, z)$ is given by (Reference M2)

$$
\psi(r, z)=\varphi_{S}(z)+v_{0} a \int_{0}^{\infty} d u e^{-u z} J_{1}(a u) J_{0}(u r)
$$

where $J_{n}(z)$ is the Bessel function of the $n^{\text {th }}$ order, and $\psi_{s}(z)$ is the potentlal due to the sheath alone. The resulting electric field at the surface of the large disc $(z=0)$ is

$$
\vec{E}(r, 0)=\hat{K}\left\{v_{0} a \int_{0}^{\infty} d u J_{1}(u a) J_{0}(u r)-\left.\frac{\partial \varphi_{S}(z)}{\partial z}\right|_{z=0}\right\} r \neq a
$$

where $\widehat{K}$ is a unit vector in the positive $z$ direction. It is assumed that the fringing in the gap between the small disc and the large plate is negligible except when $r=a$. It is apparent that there exists a value of $r$, say $r_{0}$, such that 


$$
\vec{E}\left(x_{0}, 0\right)=0
$$

The virtual electric fleld line which terminates at $r_{0}$ is called a separatrix because It generates a surface which separates two regions of space with different properties. As is seen in Figure 13, those field lines which are Inside the separatrices terminate on the small disc with radius a: while those field lines which are outside the separatrices terminate on the large disc. Thus, positive lons starting at rest inside the surface will strike the small disc, whlle those outside will not. Therefore, the effective collecting area is not $\pi \mathrm{a}^{2}$ but more nearly $\pi \mathrm{r}_{0}{ }^{2}$ where $\mathrm{r}_{\mathrm{o}}$ is given by

$$
v_{0} a \int_{0}^{\infty} d u u J_{1}(u a) J_{0}\left(u r_{0}\right)=\left.\frac{\partial \varphi_{S}(z)}{\partial z}\right|_{z=0}
$$

Now the electric fleld at the surface due to the sheath alone is approximately (L2)

$$
\left.\frac{\partial \varphi_{S}}{\partial z}\right|_{z=0} \approx-\frac{\varphi_{S}(0)}{\lambda_{D}}=-\frac{K T}{e \lambda_{D}} \cos \frac{M_{+}}{M_{-}}
$$

where it is assumed that the lons are in equilibrium with the electrons at a temperature $T$. On the other hand, 


\section{SUPERPOSED PROBE AND SHEATH FIELDS}

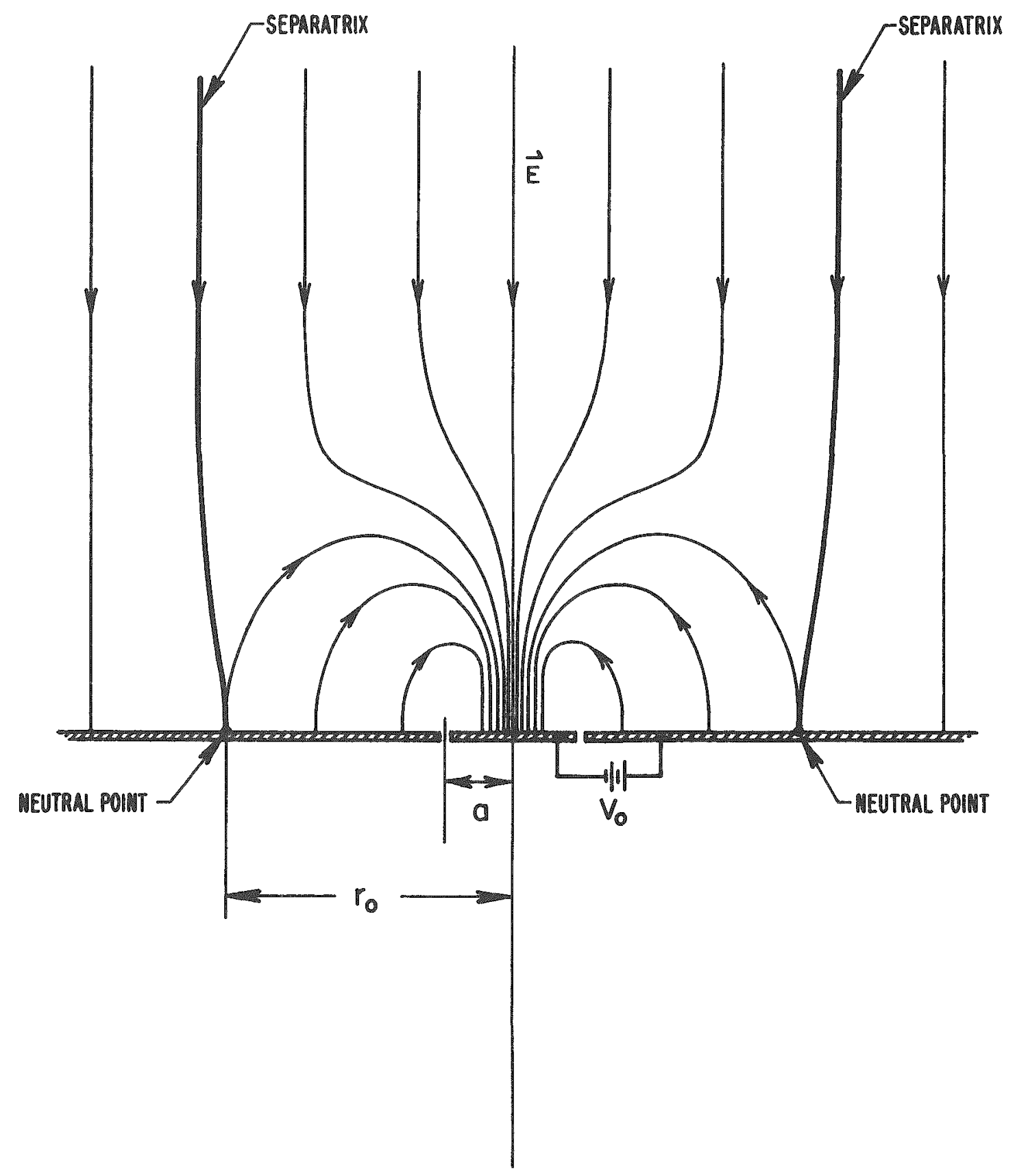




$$
\begin{aligned}
\int_{0}^{\infty} d u J_{1}(\mathrm{ua}) \mathrm{J}_{0}\left(\mathrm{ur}_{0}\right) & =-\frac{a}{2 r^{3}} 2^{F_{1}}\left(\frac{3}{2}, \frac{3}{2} ; 2 ; \frac{a^{2}}{r^{2}}\right) \\
& =-\frac{2}{\pi a r}\left\{\frac{E\left(\frac{a}{r}\right)-\left(1-\frac{a^{2}}{r^{2}}\right) K\left(\frac{a}{r}\right)}{1-\frac{a^{2}}{r^{2}}}\right\}
\end{aligned}
$$

where ${ }_{2} F_{1}(a, b ; c ; z)$ is a hypergeometric function and $K(z)$ and $E(z)$ are complete elliptic integrals of the flrst and second kind, respectively. Since ${ }_{2} F_{1}(a, b ; c ; z) \underset{z \rightarrow 0}{\longrightarrow} 1, r_{0}$ is roughly given by

$$
\frac{V_{0} a}{2 r_{0}^{3}} \approx \frac{K T}{e^{\lambda}} \ln \frac{M}{M} \text { for } V_{0}>\frac{2 a}{\lambda_{D}} \varphi_{S}(0)
$$

Note that when $V_{0}<2\left(a / \lambda_{D}\right) \varphi_{s}(0)$, the effective collecting area is $\pi a^{2}$; to satisfy this condition, it is necessary that $a>>\lambda_{D}$ because $V_{0}>\varphi_{S}(0)$ for lon saturation current measurements, but since, by assumption

$$
a \approx \lambda_{D}
$$

It is obvious that the effective aperture is governed by the applied voltage, $\mathrm{V}_{0}$. This has some interesting but, for the experimenter, unfortunate consequences. For $I_{+}$, the lon drift current is given by

$$
I_{t} \approx e n_{t} v \pi r_{0}^{2}=e n+v A \frac{r_{0}^{2}}{a^{2}}
$$


where $v \approx \sqrt{\mathrm{KT} / \mathrm{M}_{+}}$and $\mathrm{A}$ is the area of the small disc. This implies that $I_{+}$as a function of $V_{0}, n_{+}$, and $T$ and $A$ varies according to

$$
I_{+} \sim\left(V_{0} A n_{+} T^{1 / 4}\right)^{2 / 3}
$$

$1_{1} e_{0}$, the positive current depends on the applied voltage $V_{0}$ and, furthermore, the dependence on the other parameters is considerably weaker than that for a Langmuir probe.

A further complication in interpretation of data arises when one allows for collisions. Under the circumstances pertinent to this discussion collisions cannot be neglected unt!l

$$
\mathrm{r}_{0}<\ell
$$

Since $r_{0}>a$, this condition is not satisfied until an altitude is reached higher than that at which

$$
\mathrm{a}<<\ell
$$

When effects of collisions must be accounted for, to a good approximation, the resulting current $I_{+C}$ is given by $(\mathrm{S} 3) *$

*This expression goes to the correct limit of unity when $\ell / L$ becomes very large. However, it seems to fail when $\ell / L$ is of the order of unity. The reason for it is that the correction factor is a monotonically decreasing function of $\ell / L$. On the other hand, as shown in S4, when there is only one collision in the sheath the current to the probe is higher than when there are no collisions because the ions in orbits not intersecting the probe lose some energy in a single collision and descend into orbits intersecting with the probe. This effect has been verifled experimentally by Schulz and Brown. 


$$
I_{+C} \approx \frac{I+}{2}\left(\frac{3-e^{-h / l}}{1+\frac{L}{l}}\right)_{\frac{l}{L} \rightarrow 0} \frac{3 I+\frac{\ell}{2}}{L}
$$

where L Is some characteristic length associated with the probe. Since the sheath is perturbed by the applied voltage, $V_{0}$, one could argue that $\mathrm{L}$ should be set to $r_{0}$. If this is true then using $r_{0}$ from Equation (19) in Equation (22)

$$
I_{+C}-\left(n^{5 / 2} V_{0} A T\right)^{1 / 3} \ell
$$

Until more data are avallable, it is impossible to judge if Equation (23) is correct rather than one resulting from equating $\mathrm{L}$ to, say, a. From the analytical point of view, it is hopeless to resolve this problem, in particular because the geometry has been overidealized with respect to a situation which exists in the actual experiment where the small disc has the same dimensions as the radius of curvature of the "large area disc" - viz. the rocket body. One might attempt a purely numerical approach to the problem; however, this does not seem warranted at present. However, because the various parameters enter in fixed relationships, one could conceivably perform a serles of measurements with varying $V_{0}$ and $A$ and, hence, establish the correct model by determining the exponent.

In recent literature on the subject of rocket-borne experiments, it is customary to neglect the effects of negative sheaths due to photoemission, on the grounds that the measured photoeffect current is small. To show the possible fallibility of this criterion, consider an infinite metallic plane with a hole at its center (Figure 14). A circular disc whose diameter is slightly smaller than that of the hole is placed concentrically in the hole and connected electrically to the large disc by means of resistance $R$. Assume now that the two discs are 


\section{PHOTOELECTRIC EFFECT ON AN INSULATED PLATE}

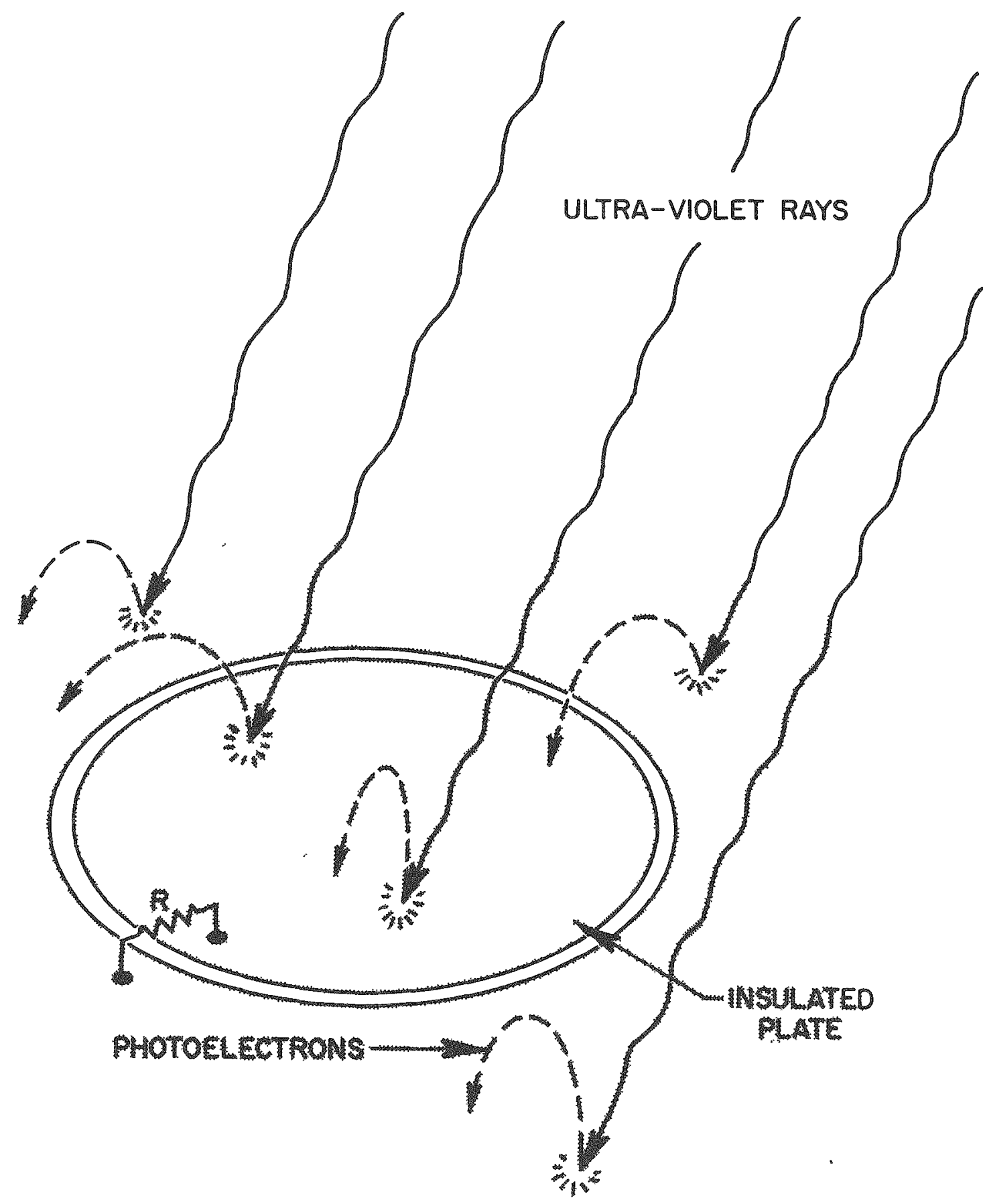


made of the same material and then illuminated uniformly with, say, vacuum UV. Then from the symmetry of the arrangement, it is selfevident that no significant voltage will appear across $R$ and, hence, no current will flow through it even though, because of photo-emission, electrons may leave the disc in great profusion (Reference O1). If the central disc is significantly smaller than the hole, or if that disc is made of material with a different work function than that of the large disc, then the deficit or excess of photoelectron flux from it will be made up by a current through the resistance $R$. The above serves to drive home the point that photoelectron currents as measured with probes may have little to do directly with the density of photoelectrons in the vicinity of the probe, to say nothing of the effect of such a negative charge sheath on the positive sheath as is the case for the positive ion collecting mode. Here it should be mentioned that in some simple geometries amenable to exact analysis, it is found that the interaction of the photoelectron sheath with a plasma may lead to instabilities similar to the well known two-stream instability (O2). It should be mentioned further that the measured currents attributed to the photoelectric effect, $10^{-9}$ to $10^{-8} \mathrm{am} / \mathrm{cm}^{2}$ (Reference B6) are comparable with what one would obtain from thermoelectric effect observable upon non-uniform heating of two dissimilar metals.

Notwithstanding the theoretical difficulties enumerated above, at least in principle, one could calibrate each individual RPA under laboratory conditions, e.g., a supersonic tunnel, before launching it into the ionosphere. The diameter of such a tunnel would have to be many Debye lengths in order to insure a clearcut separation between the sheaths formed around the nusecone and the interior wall of the tunnel. There is only one tunnel known to have such dimensions and that is the one at Arnold Air Force Base, Tullahoma, Tenn. According to its original design parameters, it is understood to simulate supersonic flight conditions up to about $50 \mathrm{~km}$. 
While on the subject of calibration of the RPA, it is worth remarking that it has become customary to assume that the transparency of the various grids in the RPA to charged particles is about equal to the optical transparency. In this connection, one should recall the data of Reference B6 which clearly indicate that the transparency to electrons is quite different from that for positive Ions and that both are significantly at variance with the optical trans parency. 
CHAPTER IV

\section{CONCLUSIONS AND RECOMMENDATIONS}

A qualitative analysis of the performance of rocket-borne RPA ncar thermal energies has shown that the interaction of the probe with its surrounding makes it nigh impossible to retrieve precise information concerning the ambient ionospheric positive ion densities.

It has been shown that it is feasible to control the effect of shock heating on the ambient conditions by proper flight plan scheduling.

On the other hand, it seems that the self-imposed electrostatic interaction of the probe with the ionized atmosphere cannot be obviated.

It is felt that before the RPA data can be considered as an unequivocal source of precise information concerning ionospheric physics, further knowledge and understanding of the kinetics of weakly ionized gases in the transition regime (Knudsen number $\sim 1$ ) must be gained. The development of the necessary theoretical models awaits the results of controlled experiments in this regime.

Another experimental investigation of interest relates to establishing the correct dependence of the saturation current on the ion density: here one could take advantage of the fixed relationships between various parameters, whence from the results obtained by varying one easily controlled parameter, the dependence on other parameters may be deduced. 


\section{REFERENCES}

Al Allen, J.E., et al; Proc. Phys. Soc. B, 70, p. 297 (1957).

Bl Bohm, D., et al; Characteristics of Electrical Discharges in

Magnetic Fields (ed. Guthrie and Wakerling), New York, 1949.

B2 Boyd, R. L.F.; Proc. Roy. Soc. A201, p. 330 (1950).

B3 Bernstein, I. B., and Rabinowitz, I. N.; Phys. Fluids 2, 112 (1959).

B4 Boyd, R. L. F., ed.: Rocket Exploration of Outer Space, London 1954.

B5 Boyd, R. L.F., and Thompson, J.B.; Proc. Roy. Soc. A250, 102 (1959).

B6 Bourdeau, R. E. , et al; Proc. Amer. Astronautical Soc. Symp. 1961.

C1 Crain, C.; I. Geophys. Res. 68, 2167 (1963).

F1 Frankenthal, S.: Private Communication.

G1 Gllmore, F. R.; Rand Report \#1543, 1955.

H1 Hinteregger, H.E.; Proc. First Intern'l Space Science Symp. 1960.

H2 Hok, G., et al; AFCRC TN 58-616, Univ. Mich., November 1958.

Il Johnson, E. O., and Malter, L.; Phys. Rev. 80, 58 (1950).

Il Loeb, B. L.; Baslc Processes of Gaseous Electronics, Los Angeles, 1955.

I.2 Langmuir, I., and Compton, K.T.; Rev. Mod. Phys. 3, 214 (1931).

M1 Model Atmos phere

M2 Morse, P.M., and Feshbach, H。: Methods of Theoretical Physics, New York 1953.

O1 Olbert, S., and Manley, O.P.: Unpublished notes.

O2 Olbert, S.: Private Communication.

S1 Schlichting, H.; Boundary Layer Theory, New York 1960.

S2 Smith, L。G。: Tech. Report \#63-19-N, GCA, June 1963.

S3 Schulz, G.J., and Brown, S.C.; Phys. Rev. 98, 1642 (1955). 
American Science and Engmeerng, Inc., Cambridge, Mass. ANAIYSIS OF PLRFORMANCE OF A ROCKETBORNE RETARDING POTENTIAL ANALYZER by OSCAr $P$. Manlev. Air Force Cambridge Research Laboratories, Bedford, Mass. Scientific Repor - Number AFCRL64-796, 34 pages, Mar 1964.

\section{Unclassified Report}

The use cf a rocket-borne retardinu prential onalyzer (RPA) for determining positive ion densities in the ionos phere is studied. It is shown that at the altutudes of interest $(40 \mathrm{to} 90 \mathrm{~km})$ shock $10 \mathrm{nization}$ induced by the nose-cone may exceed ambient inization. Morenver, the positive son current measured by means of the RPA is not linearly dependent on the ion density; at presert, the precise functional dependence between the tw: quantities cannot be established andytically.
1. Potential Analyzers.

2. Langmuir Probes.

3. Ionospheric Medsurements.

4. Rocket Measurements.
American Science and Engineerng, Inc., Cambridge, Mass., ANALYSIS OT PERFORMANCE OF A ROCKETBOPNE RETARDING POTENTIAL ANAIXZER by OsCar P. Manley Aur Force Cambridge Research Laboratories, Bedford, Mass. Scuentific Report - Number AFCRI $64-796,34$ pages, May 1964.

\section{Unclassified Report}

The use of a rocket-borne retarding potental analyzer (RPA) for determining positive ion densities in the $10 n o s p h e r e$ is studied. It is shown that at the altitudes of interest $(40$ to $90 \mathrm{~km}$ ) shock somzation induced by the nose-cone may exceed ambient ionization. Moreover, the positive ion current measured by means of the RPA is not lmearly dependent on the ion density; at present, the precise functional dependence between the two quantuties cannot be established analytically.
American Science and Engmeering, Inc., Cambridge, Mass., ANALYSIS OF PERFORMANCE OF A ROCKETBORNE RETARDING POTLNTIAL ANALYZER by Oscar P. Manley. Aur Force Cambrudge Research Laboratories, Bedford Mass Scientzfic Report - Number AFCRT$64-796,34$ pages, May 1964.

\section{Unclassified Report}

The use of a rocket-borne retarding potentral analyzer (RPA) for determining positive ion densities in the ionosphere is studied. It is shown that at the altitudes of interes ( 40 to $90 \mathrm{~km}$ ) shock lonization induced by the nose-cone may exceed ambient ionization. Moreover, the positive ion current measured oy means of the RPA is not linearly dependent on the mon density; at present, the prearse dent on the ion density; at present, the preci functional dependence between the iwo guantities cannot be established analytically.
1. Potential Analyzers.

2. Langmuar Probes.

3. Ionospherc Measurements.

4. Rocket Measurements.
American Science and Engineering, Inc. Cambridge, MasS., ANALYSIS OF PERFORMANCE OF A ROCKETBORNE RETARDING PO-ENTIAL ANALYZER by Oscar P. Manley. Arr Force Cambridge Research Laboratories, Bedford, Mass. Scientific Report - Number AFCRL$64-796,34$ pages, May 1964.

\section{Unclassıfied Report}

The use of a rocket-borne retarding potential analyzer (RPA) for determining positive ion densities in the yonosphere is studied. It is shown that at the altitudes of interest ( 40 to $90 \mathrm{~km}$ ) shock ionzation induced by the nose-cone may exceed ambient ionization. Moreover, the positive ion current measured by means of the RPA is not linearly dependent on the ion density; at present, the precise functional dependence between the two quantities camnot be established analytically.
1. Potentsal Analyzers.

2. Langmur Probes.

3. Ionospherac Measure ments.

4. Rocket Measurements.

1. Potential Analyzers.

2. Langmuir Probes.

3. Ionospheric Measurements.

4. Rocket Measurements. 